\title{
Rule-based Expert Systems for Selecting Information Systems Development Methodologies
}

\author{
Abdel Nasser H. Zaied \\ Dean, College of Computers and Informatics, Zagazig University, Egypt \\ E-mail:nasserhr@zu.edu.eg,nasserhr@gmail.com \\ Samah Ibrahim Abdel Aal \\ Teaching Assistant, College of Computers and Informatics, Zagazig University, Egypt
}

\author{
Mohamed Monir Hassan \\ Head of Information Systems Department, College of Computers and Informatics, Zagazig University, Egypt
}

\begin{abstract}
Information Systems (IS) are increasingly becoming regarded as crucial to an organization's success. Information Systems Development Methodologies (ISDMs) are used by organizations to structure the information system development process. ISDMs are essential for structuring project participants' thinking and actions; therefore ISDMs play an important role to achieve successful projects. There are different ISDMs and no methodology can claim that it can be applied to any organization. The problem facing decision makers is how to select an appropriate development methodology that may increase the probability of system success.
\end{abstract}

This paper takes this issue into account when study ISDMs and provides a Rule-based Expert System as a tool for selecting appropriate ISDMs. The proposed expert system consists of three main phases to automate the process of selecting ISDMs.

Three approaches were used to test the proposed expert system. Face validation through six professors and six IS professionals, predictive validation through twenty four experts and blind validation through nine employees working in IT field.

The results show that the proposed system was found to be run without any errors, offered a friendly user interface and its suggestions matching user expectations with $95.8 \%$. It also can help project managers, systems' engineers, systems' developers, consultants, and planners in the process of selecting the suitable ISDM. Finally, the results show that the proposed Rule-based Expert System can facilities the selection process especially for new users and nonspecialist in Information System field.

Index Terms - Information Systems, Expert Systems, Information Systems Development Methodologies

\section{Introduction}

The problem of selecting a suitable ISDM has been addressed in different ways by many researchers. McConnell [1] provided general guidelines on how to select the most suitable development lifecycle and gave practical tips on best practices for various development environments. Similarly, different authors of agile ISDM, Highsmith [2,3] provided general recommendations for adaptation and use of these ISDM. Although these general guidelines and tips were very useful; they did not include recommendations for selection of a specific ISDM. Cockburn [4] provided a decision model that helps select the suitable ISDM from a family of ISDMs named Crystal. In 2007, Mnkandla \& Dwolatzky [5] provided a tool for selecting the most appropriate agile method for a given project. According to Vavpotič \& Vasilecas [6] organizations dealing with IS development often having lack knowledge and experience to objectively evaluate different types of ISDMs. So the challenge is to automate the process of selecting ISDMs and enable decision maker to select form different types of ISDMs so that the professionals simply enter some information about the project and get an indication of the most appropriate methodology. This paper classifies organizations' problem situations and provides an overview for different types of ISDMs. Also it automates the process of selecting ISDMs using expert system.

The structure of this paper is as follows. Firstly, ISDMs were defined and discussed; then the proposed expert system components were discussed. The following section contains a description of the proposed expert system deployment and the evaluation process. The final section contains the conclusions and recommendations. 


\section{Information Systems Development Methodol ogies}

Information system development methodology refers to the framework that is used to structure, plan, and control the process of developing an information system. Avison \& Fitzgerald [7] defined an IDSM as "a system of procedures, techniques, tools and documentation aids which help system developers to implement a new information system". Whereas, Whitten et al. [8] defined IDSM as "a very formal and precise system development process that defines a set of activities, methods, best practices, deliverables, and automated tools for system developers and project managers to use to develop and maintain most or all Information Systems and software".

\subsection{Types of Information Systems Development Methodol ogies}

There are many types of ISDMs used to develop and improve information systems. The methodology initiatives of the early-methodology era of the 1970s and early 1980 s were characterized by their ability to structure and control the development process. These methodologies include:

- Process Oriented Methodologies such as Structured Analysis Design and Implementation of Information Systems (STRADIS) methodology [9] and Jackson systems development methodology (JSD) [10];

- Holistic methodologies such as Soft Systems methodology (SSM) [11];

- Data-Oriented Methodologies such as Information engineering methodology (IE) [12];

- Blended Methodologies such as Structured System Analysis and Design methodology (SSADM) [13];

- Object-oriented methodologies such as ObjectOriented Analysis and Design (OOAD) methodology, Prototyping, Rapid Application Development methodology (RAD) [14];

- Socio-technical methodologies such as Effective technical and human implementation of computer based systems methodology (ETHICS) [15], Information systems work and analys is of change methodology (ISAC); and

- Frameworks such as Multi-view framework [16].

In the mid-1990s agile methodologies were evolved as a part of reaction against the traditional methodologies. The goal of agile methodologies is to address the perceived limitations of formal methodologies based on the traditional System Development Life Cycle (SDLC) such as long system development time, rigorous and inflexible requirements management. Agile methodologies include:
- Scrum (SM) methodology [17];

- Adaptive Software Development methodology [17];

(ASD)

- EXtreme Programming (XP) methodology [18];

- Dynamic systems development method (DSDM) [19]; and

- Feature-driven development (FDD) methodology [19].

\subsection{Selecting Information Systems Development Methodol ogy}

The number of information systems development methodologies has increased and software engineers have struggled to select methodology appropriate for all applications. But there is no single methodology that will work for all development situations. Then the challenge is how to select the appropriate ISDMs? Therefore, it is useful to use expert system as a selection tool to automate the process of selecting the suitable ISDM. Expert systems are interactive computer programs that mimic and automate the decision making and reasoning processes of human experts in solving a specific domain problem, through delivering expert advice, answering questions, and justifying their conclusions [20]. Seflek \& Carman [21] defined expert system as "A program that uses available information, heuristics, and inference to suggest solutions to problems in a particular discipline".

\section{Proposed Expert System}

The proposed expert system is a rule-based expert system; it consists of three main phases as shown in Fig. 1.

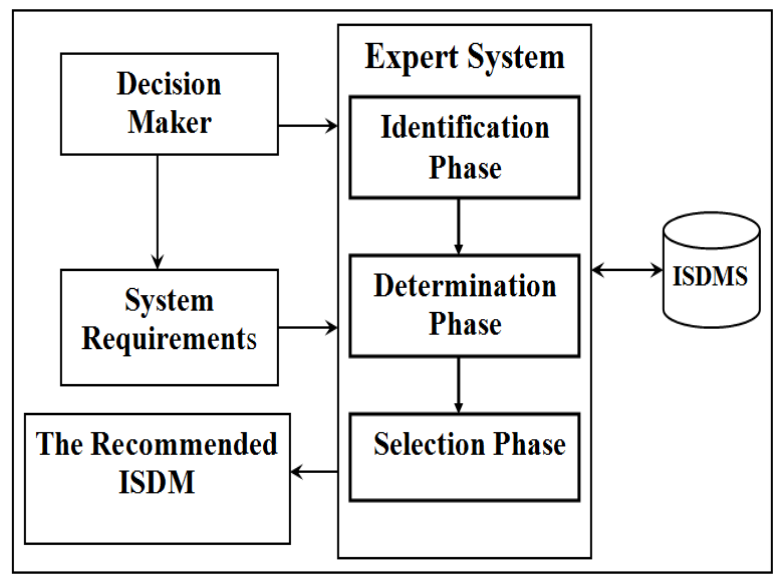

Fig. 1: Proposed system framework

Phase I: Identification Phase in which the Information systems problem situations had been identified and classified into four types: 
○ Technical problem situation;

○ Social problem situation;

○ Socio-technical problem situation; and

○ Complex problem situation.

Phase II: Determination Phase in which a group of suitable types of ISDMs were selected based clarity and stability of user requirements, development time, familiarity with technology system complexity, and system criticality as shown in table (1).

Phase III: Selection Phase in which a specific methodology was selected based on the objectives and goals of each methodology as shown in Appendix (A).

Table 1: Problem Situations and corresponding methodologies

\begin{tabular}{|l|l|}
\hline \multicolumn{1}{|c|}{ Problem Situation } & \multicolumn{1}{c|}{ Methodologies } \\
\hline Technical problem situation & $\begin{array}{l}\text { Traditional methodologies, Agile methodologies, Rapid Application Development } \\
\text { methodology, and Prototyping. }\end{array}$ \\
\hline Social problem situation & Holistic methodologies. \\
\hline Socio-technical problem situation & Socio-Technical methodologies. \\
\hline Complex problem situations & Frameworks. \\
\hline
\end{tabular}

\section{The Proposed Expert System Development}

The design of the proposed system evolves, four common design issues: system response time, user help facilities, error information handling, and command labeling.

\subsection{System Design Tool}

Visual Rule Studio (an object-oriented COMcompliant expert system development environment for windows) was used to develop the prototype expert system.

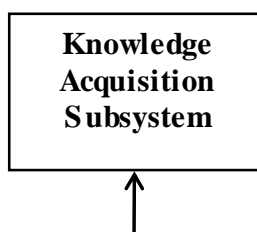

Expert
Visual Rule Studio installs as an integral part of Microsoft Visual Basic as an ActiveX Designer.

\subsection{Proposed System Components}

The core components of proposed expert systems are the knowledge base and the reasoning engine as shown in Fig. 2.
Knowledge acquisition subsystem: the main source of knowledge was published materials. The knowledge had been built according to the selection criteria, it was sent to professors and IS professionals to chick and recommend any modifications.

Knowledge base: The knowledge base was developed to aid in the process of selecting the suitable ISDMs. Twenty One ISDMs and 101 Rules were used as shown in Appendix (B).

Explanation subsystem: A subsystem that explains the system's actions.

Inference engine: The inference engine performs the role of inferring the required decision from the knowledge base. In the proposed expert system; forward chaining engine was used.

User interface: The interactions between the users and the system were supported through a friendly graphical user interface running under windows environment.

\subsection{System Description}

The proposed system consists of 18 screens representing all system phases; the first screen is welcome screen as shown in Fig. 3. The next three screens represent Phase (I) inputs which provide three questions should be answered with YES or NO to define the problem situation. 
Fig. 4 shows an example of these screens. At the end of phase (I), the user can move to the next screen which provides a determination of the problem situation.

Once the problem situation has been determined the user can continue and move to the next six screens which provide six questions should be answered also with YES or NO to determine a group of information systems development methodologies. Fig. 5 shows an example of these screens.

\section{Wellcome to}

\section{An advisory Rule-Based Expert System for}

\section{selecting Infomation Systems Development}

This program will help you to select the suitable Infomation Systems

Development Methodology for developing your system.

Continue

Exit

Fig. 3: Welcome screen

To determine the type of your problem situation, please answer the following question with Yes or No

[3] - Do you have a combination of human and computer problems ?

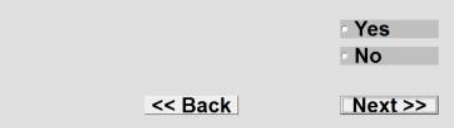
Exit

Fig. 4: An example of phase I screens

The suitable ISDMs that you need to use are the Agile Methodologies

The agile methodologies are a group of ISDMs that share common characteristics but each methodology of this group has its own objectives and goals to determine which one is suitable, please continoues $\ll$ Back Next $\gg$ Exit

Fig. 5: An example of phase II screens

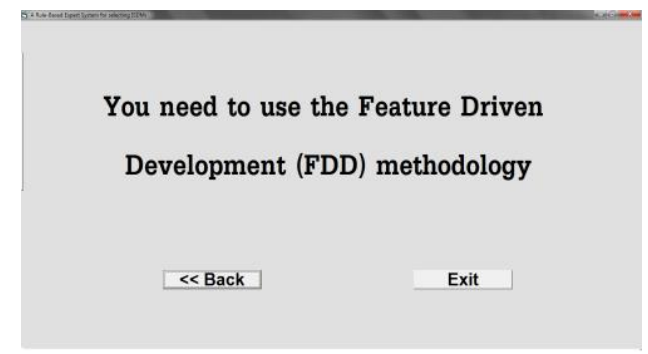

Fig. 6: An example of phase III screens
At the end of phase (II), the user can move to the next screen which provides a list of objectives the user should choose one so that the proposed system can recommend a specific methodology in the final phase, Fig. 6 shows an example of these screens.

\section{System Validation}

Software testing is a critical element of software quality assurance and represents the ultimate review of specification, design, and code generation. In this work, three approaches were used to test the proposed expert systemas shown in Fig. 7, these approaches were:

1-Face validation (was used during designing phase).

2-Predictive validation (was used during testing and validation phase).

3-Blind validation (was used during testing and validation phase).

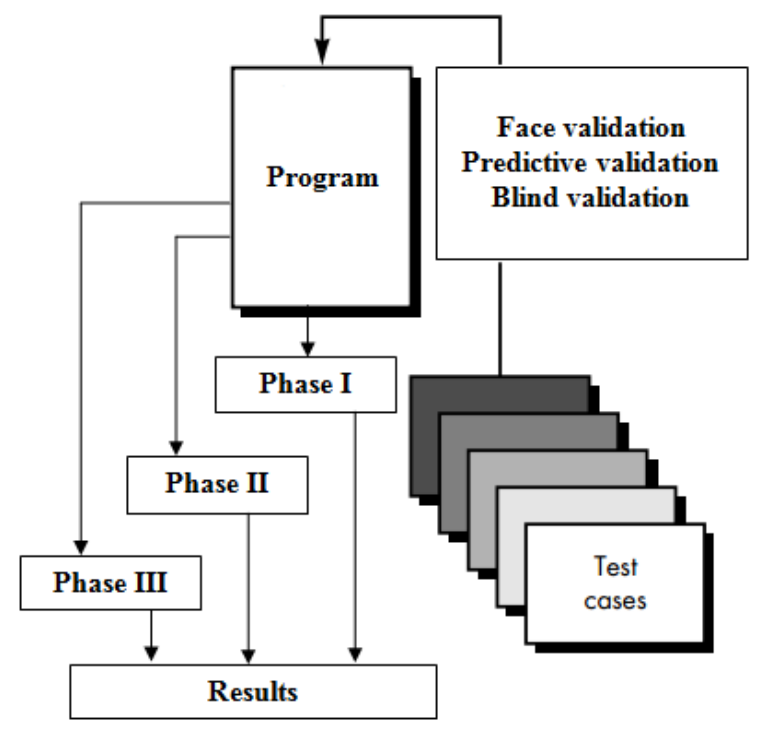

Fig. 7: Test Plan Procedure

\subsection{Face validation}

Face validation is useful as a preliminary approach for system validation. This validation was accomplished during the development process through six professors and six IS professionals to ensure that the knowledge embedded within the expert system is accurate; to ensure the reliability of the proposed system, and to ensure that all parts related to the proposed system will work correctly and consistently.

\subsection{Predictive Validation}

Predictive validation requires using historic test cases; four groups were used. Each group had six experts. Twenty four experts were attained a special awareness sessions to explain the proposed system 
components and to train them on how to use the proposed system.

\subsection{Blind Validation}

Blind validation aims to validate the proposed system performance when used by non-expert users. Five companies were selected based on a recommendation from Cairo Chamber of Commerce (CCC), Egypt. After personal contact, one company was agreed to participate in the study. A group of nine employees working in IT department were selected by company manager. Awareness session was conducted, then each participant tested the proposed system and write down his comments.

\section{Results Analysis and Discussion}

\subsection{Predictive Validation Results}

Twenty participants out of twenty four selected Technical problem situation; two selected Complex problem situation; one selected Social problem and one selected Socio-Technical problem situation. The participants suggested fifteen different methodologies through twenty four suggestions.

Only one mis match between user expectation and system output, the user selected Object Oriented Analysis and Design (OOAD) Methodology and the system suggested Structured System Analysis and Design methodology (SSADM) with the prototyping approach.

\subsection{Blind Validation Results}

The results of the Blind validation can be summarized as follows:

Availability and clarity of actions attribute: The proposed system was found to be a consistent from page to page with available actions, including meaningful titles, meaningful buttons in name and actions as shown in table (2).

Table 2: Participants' opinions based on availability and clarity of actions attribute

\begin{tabular}{|c|c|c|}
\hline \multirow{2}{*}{$\begin{array}{c}\text { Participants' } \\
\text { opinions }\end{array}$} & \multicolumn{2}{|c|}{ Availability and clarity of actions } \\
\cline { 2 - 3 } & No. & Percentage \\
\hline Excellent & 2 & $22.22 \%$ \\
\hline Very good & 3 & $33.33 \%$ \\
\hline Good & 4 & $44.45 \%$ \\
\hline Bad & 0 & $00.00 \%$ \\
\hline Total & $\mathbf{9}$ & $\mathbf{1 0 0 . 0 0 \%}$ \\
\hline
\end{tabular}

Consistency of font sizes and colors attribute: In most cases the font sizes and colors of the proposed systemwas found to be good as shown in table (3).

Table 3: Participants' opinions based on consistency of font sizes and colors

\begin{tabular}{|c|c|c|}
\hline \multirow{2}{*}{$\begin{array}{c}\text { Participants } \\
\text { opinions }\end{array}$} & \multicolumn{2}{|c|}{ Consistency of font sizes and colors } \\
\cline { 2 - 3 } & No. & Percentage \\
\hline Excellent & 1 & $11.11 \%$ \\
\hline Very good & 3 & $33.33 \%$ \\
\hline Good & 5 & $55.56 \%$ \\
\hline Bad & 0 & $00.00 \%$ \\
\hline Total & $\mathbf{9}$ & $\mathbf{1 0 0 . 0 0 \%}$ \\
\hline
\end{tabular}

Free of errors attribute: The proposed systemwas found to be run without any errors as shown in table (4).

Table 4: Participants' opinions based on free of errors attribute

\begin{tabular}{|c|c|c|}
\hline \multirow{2}{*}{$\begin{array}{c}\text { Participants } \\
\text { opinions }\end{array}$} & \multicolumn{2}{|c|}{ Free of errors } \\
\cline { 2 - 3 } & No. & Percentage \\
\hline Excellent & 9 & $100 \%$ \\
\hline Very good & 0 & $00.00 \%$ \\
\hline Good & 0 & $00.00 \%$ \\
\hline Bad & 0 & $00.00 \%$ \\
\hline Total & $\mathbf{9}$ & $\mathbf{1 0 0 . 0 0 \%}$ \\
\hline
\end{tabular}

User-friendliness attribute: The participants found that the proposed system offers a friendly user interface as shown in table (5).

Table 5: Participants' opinions based on user-friendliness interface attribute

\begin{tabular}{|c|c|c|}
\hline \multirow{2}{*}{$\begin{array}{c}\text { Participants } \\
\text { opinions }\end{array}$} & \multicolumn{2}{|c|}{ User-friendliness } \\
\cline { 2 - 3 } & No. & Percentage \\
\hline Excellent & 2 & $22.222 \%$ \\
\hline Very good & 3 & $33.333 \%$ \\
\hline Good & 4 & $44.444 \%$ \\
\hline Bad & 0 & $00.00 \%$ \\
\hline Total & $\mathbf{9}$ & $\mathbf{1 0 0 . 0 0 \%}$ \\
\hline
\end{tabular}

Acceptability attribute: The proposed system was found to be acceptable and helpful in the process of selecting the suitable information system development methodology as shown in table (6). 
Table 6: Participants' opinions based on acceptability attribute

\begin{tabular}{|c|c|c|}
\hline \multirow{2}{*}{$\begin{array}{c}\text { Participants } \\
\text { opinions }\end{array}$} & \multicolumn{2}{|c|}{ Acceptability } \\
\cline { 2 - 3 } & No. & Percentage \\
\hline Acceptable & 9 & $100.00 \%$ \\
\hline Not acceptable & 0 & $00.00 \%$ \\
\hline Total & $\mathbf{9}$ & $\mathbf{1 0 0 . 0 0 \%}$ \\
\hline
\end{tabular}

\section{Conclusion}

This research provides a rule based expert system that automates the process of selecting Information Systems Development Methodologies (ISDMs). Based on this work, it can be extract the following conclusions:

1. The proposed system could help developers, consultants, and planners in the process of selecting the suitable ISDMs by covering different types of problem situations and enabling them to select a specific Information Systems Development Methodology rather than selecting a family of methodologies as in Cockburn [4]; Carroll [22]; Mnkandla \& Dwolatzky [5] and Yusof et al [23].

2. The results show that the proposed system suggestions matching user expectations with $95.8 \%$.

3. The use of the hybrid expert system shell Visual Rule Studio, which runs together with Microsoft Visual Basic 6.0, was found to be very effective in producing the system under the popular Windows environment.

4. Finally, the proposed system was found to be acceptable and helpful in the process of selecting the suitable information system development methodology.

\section{References}

[1] McConnell S. Rapid development: taming wild software schedules. Microsoft Press, Redmond, Wash, 1996.

[2] Highsmith A. Adaptive Software Development: A Collaborative Approach to Managing Complex Systems. New York, NY: Dorset House Publishing, 2000.

[3] Highsmith J. Agile Software Development Ecosystems. Addison Wesley, 2002.

[4] Cockburn A. Agile software development: agile software development series. Addison-Wesley, Boston, 2002.

[5] Mnkandla E., Dwolatzky B. Agile Methodologies Selection Toolbox". International Conference on Software Engineering Advances ICSEA, 2007.
[6] Vavpotič D., Vasilecas O. Selecting a Methodology for Business Information Systems Development: Decision Model and Tool Support. ComSIS, 2012, 9(1): $136-164$.

[7] Avison, D., Fitzgerald G. Information Systems Development: Methodologies, Techniques and Tools. $2^{\text {nd }}$ Edition. McGraw-Hill, London, 1995.

[8] Whitten J., Bentley L., Dittman K. Systems analysis and design methods. $6^{\text {th }}$ edition, McGraw-Hill, Boston, Mass, 2004.

[9] Gane C., Sarson T. Structured Systems Analysis: Tools and Techniques. Prentice Hall, Englewood Cliffs, New Jersey, 1979.

[10] Jackson M. Systems Development. UK: Prentice Hall, 1983.

[11] Checkland P. Systems Theory: Systems Practice. Chichester: John Whiley, 1981.

[12] Martin J. Information Engineering: A Trilogy. Prentice Hall, Englewood Cliffs, New Jersey, 1989.

[13] Ashworth C., Goodland M SSADM: A Practical Approach. McGraw- Hill, Maidenhead, 1990.

[14] Martin J. Rapid Application Development. Macmillan Publishing, New York, 1991.

[15] Mumford, E. Effective systems design and requirements analysis: The ETHICS method. Basingstoke, UK: Macmillan Press, 1995.

[16] Avison D., Wood-Harper A., Vidgen R., Wood J. A further exploration into Information systems development: the evolution of Multiview2. Information Technology \& people, 1989, 11(2): 111.

[17] Stojanovic Z., Dahanayake A., Sol H. Modeling and Architectural Design in Agile Development Methodologies. $8^{\text {th }}$ CAISE/IFIP8.1 International Workshop on Evaluation Methods in System Analysis and Design EMMSAD, 2003: 180-189.

[18] Gerber A., Van Der Merwe A., Alberts R. Practical Implications of Rapid Development Methodologies. Computer Science and IT Education Conference, 2007: 234-245.

[19] Ramsin N., Paige R. Process-Centered Review of Object Oriented Software Development Methodologies. ACM Computing Surveys, 2008, 40(1): $1-89$.

[20] Zaied A. Irrigation Support Expert System for Small Scale Farms. $23^{\text {rd }}$ Engineering Conference Toward Development and Integration of Engineering Infrastructure in the Arab World Bahrain, 2005: 1-9.

[21] Seflek A., and Carman K., (2010), "A design of an expert system for selecting pumps used in agricultural irrigation", Mathematical and 
Computational Applications, Vol. 15, No. 1, pp. 108-116.

[22] Carroll J. The Process of ISD Methodology Selection and Use: A Case Study. European Conference on Information Systems - ECIS, 2003: $1-11$.
[23] Yusof M., Shukur Z., Abdullah A. CuQuP: A Hybrid Approach for Selecting Suitable Information Systems Development Methodology. Information Technology Journal, 2012, 10(5): 1031-1037.

\section{Appendix (A): ISDMs Objectives and Goals}

\begin{tabular}{|c|c|c|}
\hline $\begin{array}{l}\text { Problem } \\
\text { Situation }\end{array}$ & Methodology & Objectives and Goals \\
\hline \multirow[t]{13}{*}{ Technical } & STRADIS & It focuses on the analysis and design of the processes that underlie the IS. \\
\hline & IE & It focuses on the dat a aspects of within information systems \\
\hline & JSD & $\begin{array}{l}\text { It focuses on the analysis and design of the processes that underlie the IS and focuses technicalaspects } \\
\text { in the soft ware development life cycle }\end{array}$ \\
\hline & YSM & $\begin{array}{l}\text { It focuses on the analysis and design of the processes that underlie the IS and can be applied for the } \\
\text { small projects }\end{array}$ \\
\hline & SSADM & Focus on both the data and the processes aspect of system to information systems. \\
\hline & MERISE & $\begin{array}{l}\text { focus on both data and process aspect of the information system and separate the dataprocessing to } \\
\text { modify dat a without affect the entire project }\end{array}$ \\
\hline & Prototyping & $\begin{array}{l}\text { Prototyping used for speeds up the development process when the project is small. It may be } \\
\text { incorporated into the SDLC or other approaches as an improved way of systems investigation, }\end{array}$ \\
\hline & OOAD & $\begin{array}{l}\text { It used for developing encapsulated information system, ensuring re-usability, and standardizing of } \\
\text { objects which increases design understanding and decreases the risk associated with project development }\end{array}$ \\
\hline & Scrum & $\begin{array}{l}\text { it used for Managing and controlling it erative and incremental processes during the software } \\
\text { development }\end{array}$ \\
\hline & The XP & it used for Satisfying cust omer needs and maintain effective teamwork \\
\hline & ASD & $\begin{array}{l}\text { It used for managing software development projects which are under intense time pressure and have } \\
\text { rapidly changing requirements. It provides a framework on how to encourage collaboration and learning } \\
\text { within the project }\end{array}$ \\
\hline & DSDM & $\begin{array}{l}\text { Its goal is to deliver systems on time and on budget while adjusting for changing requirements along the } \\
\text { development process }\end{array}$ \\
\hline & FDD & It used for producing frequent, tangible, working results \\
\hline Social & Soft System & $\begin{array}{l}\text { To enhance an analyst understands of a problem situation. And Facilitating the management of the social } \\
\text { systems aspects of Information Systems. }\end{array}$ \\
\hline \multirow{5}{*}{$\begin{array}{l}\text { Socio- } \\
\text { technical }\end{array}$} & EIHICS & It used to achieve job satisfaction where there is a high user interaction with the system. \\
\hline & ISAC & $\begin{array}{l}\text { The main objective of this methodology is to analyze the change of technology, communication } \\
\text { interfaces, and the change of data, entities and processes }\end{array}$ \\
\hline & $\begin{array}{l}\text { Human } \\
\text { Centered } \\
\text { Design }\end{array}$ & $\begin{array}{l}\text { Provide an understanding and specification of the context in which the system will be used, and } \\
\text { consideration of social and cultural factors, and including working practices and the structure of the } \\
\text { organization. }\end{array}$ \\
\hline & $\begin{array}{l}\text { Socio- } \\
\text { technical } \\
\text { method }\end{array}$ & $\begin{array}{l}\text { It is used to identify tasks that have to be allocated to machines and the tasks that have to be performed } \\
\text { by humans (both individually, and as teams). }\end{array}$ \\
\hline & CSE & $\begin{array}{l}\text { CSE deal with both analysis of the organizational issues, and offers some practical support for systems } \\
\text { design }\end{array}$ \\
\hline $\begin{array}{c}\text { Socio- } \\
\text { technical }\end{array}$ & RAD & The main objective of the RAD methodology is to reduce the development time of systems \\
\hline complex & Frameworks & $\begin{array}{l}\text { Frameworks provide an exploration in information systems development. It takes on different } \\
\text { perspectives or views: organizational, technical, human -oriented, economics and so on. It brings together } \\
\text { techniques from multiple methodologies }\end{array}$ \\
\hline
\end{tabular}

\section{Appendix B: Sample of Rules}

- Rule 1: IF problem is structured and defined and IF problem has an unclear objective and IF problem is not combined of behavior, organization, and, technical factors THEN the problem situation is a technical problem

- Rule 4 : IF problem is not structured and defined and IF problem has clear objectives and IF problem 
is comb ined of behavior, organization, and, technical factors THEN the problem situation is a sociotechnical problem

- Rule 5 : IF problem is structured and defined and IF problem has unclear objectives and IF problem is combined of behavior, organization, and, technical factors THEN the problem situation is a complex problem

- Rule 8 : IF problem is not structured and defined and IF problem has unclear objectives and IF problem is not combined of behavior, organization, and, technical factors THEN the problem situation is a social problem

- Rule 19 : IF the problem situation is technical problem and IF user has not a clear requirement and IF user has not a critical System and IF user has not a complex System and IF user will not use unfamiliar technology and IF user has not unstable Requirements and IF user has not a short time for developing his system THEN the suitable ISDMs are the Traditional methodologies

- Rule 52 : IF the problem situation is technical problem and IF user has a clear requirement and IF user has not a critical System and IF user has not a complex System and IF user will not use unfamiliar technology and IF user has not unstable Requirements and IF user has a short time for developing his system THEN the suitable ISDM is the prototyping

- Rule 53 : IF the problem situation is technical problem and IF user has a clear requirement and IF user has not a critical System and IF user has not a complex System and IF user will not use unfamiliar technology and IF user has unstable Requirements and IF user has not a short time for developing his system THEN the suitable ISDMs are the Agile Methodologies

- Rule 83 : IF the suitable ISDMs are the Agile Methodologies and IF the user wants to manage and control the iterative and incremental projects THEN the suitable methodology is the Scrum methodology

- Rule 84 : IF the suitable ISDMs are the Agile Methodologies and IF the user wants to satisfy customer needs and maintain effective teams THEN the suitable methodology is the eXtreme Programming (XP) methodology

- Rule 88: IF the suitable ISDMs are Traditional methodologies and incorporate the Throwaway Prototyping into the SDLC and IF the user wants to focus on the analysis and design of the processes of a large scale System THEN the suitable methodology is the Structured Analysis Design and Implementation of Information Systems (STRADIS) Methodology
- Rule 89 : IF the suitable ISDMs are Traditional methodologies and IF the user wants to focus on the analysis and design of the processes of a large scale System THEN the suitable methodology is the Structured Analysis Design and Implementation of Information Systems (STRADIS) Methodology

- Rule 90 : IF the suitable ISDMs are the Traditional methodologies and incorporate the Throwaway Prototyping into the SDLC and IF the user wants to focus on the analysis and design of the processes of a small scale System THEN the suitable methodology is the Yourdon Systems Method (YSM) Methodology

\section{Author's Profiles}

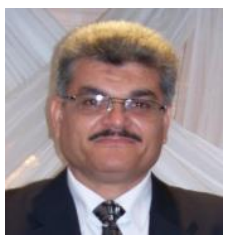

Abdel Nasser H. Zaied is a Dean, College of Computers and Informatics, Zagazig University, Egypt. Adviser to the Minister of Higher Education for private and national universities. He previously worked as an Professor of Industrial Engineering, Zagazig University Egypt; an assistant professor of Technology Management, Arabian Gulf University, Bahrain; and as visiting professor at Oakland University, USA. He supervised $10 \mathrm{PhD}$. thesis and 42 MSc. thesis, and examined $35 \mathrm{MSc}$ thesis. He published 21 research papers in International and Regional Journals and 22 research papers in International and National conferences. His areas of research are: Systems Analysis and Design; Information Security; Knowledge Management; Quality Management Systems and project Management, Electronic applications.

How to cite this paper: Abdel Nasser H. Zaied, Samah Ibrahim Abdel Aal, Mohamed Monir Hassan,"Rule-based Expert Systems for Selecting Information Systems Development Methodologies", International Journal of Intelligent Systems and Applications(IJISA), vol.5, no.9, pp.19-26, 2013. DOI: 10.5815/ijisa.2013.09.03 